\title{
The Atlantic Multidecadal Oscillations have controlled Natural Variability in Deoxygenation in the Tropical Pacific at Multi-Decadal Timescales over the Last Climatic Cycle
}

\author{
LAETITIA E PICHEVIN ${ }^{1}$, RAJA GANESHRAM ${ }^{2}$ AND \\ MASSIMO BOLLASSINA ${ }^{3}$ \\ ${ }^{1}$ Edinburgh University \\ ${ }^{2}$ School of GeoSciences, University of Edinburgh \\ ${ }^{3}$ Edinburg University \\ Presenting Author: laetitia.pichevin@ed.ac.uk
}

Marine oxygen content is predicted to decrease with global warming. Multi-decadal climatic variability such as the Pacific Decadal Oscillation (PDO) or the Atlantic Multi-decadal Oscillation (AMO) have been identified as potential controls on oxygen concentration trends over recent decades in the tropical Pacific and Atlantic Oxygen Minimum Zones (OMZs), respectively, via temperature, productivity or ventilation effects. The apparent decrease in oxygen in the North Pacific OMZ since the late 1970's has been linked to a shift from a negative to a positive phase of the PDO. However, these instrumental records of marine oxygen and climatology are short, only dating back to the 1960's, making it hard to ground truth the apparent relationship between these climate modes and marine hypoxia. Crucially, the frequency, sign and amplitudes of these climatic oscillations are expected to evolve under warming conditions, making it essential to understand their impact on marine oxygen for future prediction. Therefore, the main challenge for modelling and predicting the decline in oxygen concentration linked to climate change is our lack of knowledge of the natural variability in marine oxygen inventory in the preindustrial past and how they are related to natural modes of climate variabilities. This can be resolved by looking at past archives of marine oxygen changes.

We reconstruct denitrification, as a marker of deoxygenation, in 10 annually resolved 200 year-long records from a varved sedimentary archive in the Gulf of California OMZ (Eastern Tropical North Pacific) covering key periods over the last Glacial-Interglacial cycle (55 Ka BP). We show that anoxia in the basin is mainly controlled by sub-surface ventilation around the Equator triggering changes in oxygen delivery at these timescales. Spectral analyses on the annually resolved denitrification records reveal strong AMO periodicities in all the Holocene- and Deglacial-age records. Modern circulation data reanalyses regressed on the positive $\mathrm{AMO}$ and PDO indices reveal that the AMO has a far greater impact on the subsurface circulation in the tropical Pacific than the PDO and is therefore the most likely candidate driving natural oxygen variability in the Pacific OMZs. Future marine oxygen predictions must focus primarily on the North Atlantic climate. 